\title{
Intervention Strategies in Language Development at Preschool Age
}

Făt Silvia, Pânișoară Georgeta, Sandu Cristina, Doru Vlad Popovici 


\title{
Intervention Strategies in Language Development at Preschool Age
}

\author{
Făt Silvia $^{a^{*}}$, Pânișoară Georgeta ${ }^{a^{*}}$, Sandu Cristina ${ }^{a^{*}}$, Doru Vlad Popovici ${ }^{a^{*}}$ \\ ${ }^{a}$ Faculty of Psychology and Sciences of Education, University of Bucharest, Panduri 90, Bucharest, Romania \\ *Corresponding author: silvia.fat@fpse.unibuc.ro; georgeta.panisoara@gmail.com; chrystina29@yahoo.com; stelutadoru@yahoo.com
}

Abstract

Keywords:

\section{Communication}

Language development Intervention strategies Digital resources
Zusammenfasung

Schlüsselworte:

Kommunikation Sprachentwicklung Interventionsstrategien, Digitale Ressourcen
The article presents some focus-group results regarding the efficiency of practices in the language development at the preschool age, in order to discover the most advantageous strategies for valorizing them. The language is an essential tool of children's development which provides learning opportunities for communication and interpersonal relationships. In an attempt to describe how teachers usually intervene, the structured discussion has shown the following: the most common difficulties of children in language-centered activity, the specialized support that experts can offer in such situations, the impact of verbal behavior on the socialization in kindergarten, the treatment way of these errors by appropriate teaching methods. The game is highlighted as the most effective method of reducing vulnerable verbal behaviors in its variant as an active group method. The technology integration in language development is a popular trend in the education and language therapy. As it emerges from the discussion, teachers need more resources in addressing speech difficulties, referring in particular to digital resources. Interactive platforms such as TIMLOGORO would be extremely useful tools in the specialist intervention with which the teachers collaborate.

Der Artikel präsentiert einige Fokus-Gruppe Ergebnisse in Bezug auf die Effizienz der Praktiken in der sprachlichen Entwicklung im Vorschulalter, um die vorteilhaftesten Strategien für die Bewertung ihrer $\mathrm{zu}$ entdecken. Die Sprache ist ein wesentliches Instrument der Entwicklung der Kinder, das Lernmöglichkeiten für Kommunikation und zwischenmenschliche Beziehungen bietet. In einem Versuch zu beschreiben, wie Lehrer in der Regel eingreifen, hat die strukturierte Diskussion folgendes gezeigt: die häufigsten Schwierigkeiten der Kinder in der sprachzentrierten Tätigkeit, die spezialisierte Unterstützung, die Experten in solchen Situationen bieten können, die Auswirkungen des verbalen Verhaltens auf die Sozialisation in Kindergarten, die Behandlungsweise dieser Fehler durch entsprechende Lehrmethoden. Das Spiel wird als die effektivste Methode zur Verringerung der anfälligen verbalen Verhaltensweisen in seiner Variante als eine aktive Gruppe Methode hervorgehoben. Die Technologieintegration in der Sprachentwicklung ist ein populärer Trend in der Bildungs- und Sprachtherapie. Wie aus der Diskussion hervorgeht, benötigen die Lehrer mehr Ressourcen bei der Bewältigung von Sprachschwierigkeiten und beziehen sich insbesondere auf digitale Ressourcen. Interaktive Plattformen wie TIMLOGORO wären äußerst nützliche Werkzeuge in der Fachintervention, mit denen die Lehrer zusammenarbeiten.

\section{Introduction}

The communication is an essential feature of human life. This is the key of guiding people in the formation and the development of interpersonal relationships and permanently influencing emotional reactions and thoughts of individuals, so being a necessary process of social life (Gokyer, 2015). The communication in the educational area is considered one of the determinants of the personal and professional development of students. It acts as a mediator between us and others, but also as a mentor who supervises the actions. The relationship between the two educational actors or groups involved in the teaching process that interacts, exchanges, sends and receives meaningful information, leads to the establishment of essential features for the efficiency of the communication process.

The language is considered "a structured system of symbols used to communicate meanings" (Floyd, 2013, p.167). It is characterized by the following features: symbolic, arbitrary, governed by rules, various meanings, in close connection with context and culture. This is a verbal behaviour of the individual, including the following: speak, listen, share ideas, retaining audio messages, reproducing and translating them. Wackenheim (apud Popa, 2006, p. 42) speaks about the following functions of language: the function of integration of the individual in his environment, the function of revealing and self-disclosure, the function of valorisation, the function of regulating the behaviour of others, the therapeutic function. When talking about the expressivity of language, we distinguish between internal language in speech and external language through speech. The expression of language involves both logical learning and creative learning. In order to express significant meanings, a harmonious blend between content and intonation or accent is required.

Interaction with teachers provides access to vocabulary enrichment and interaction in the school environment, engages students in interactive reading, all of which are important activities and support for the development of children's language at preschool age. (Berk, 2013) 


\section{Characteristics of language development}

The developing children's language is a complex process that differs from one child to another. However, there are many common features of language development among children from the same society or the same language but also among many children who speaks different languages. The linguistic development of a child is a divergent, dynamic, flexible process, depending on many internal and external factors. However, there are some features that can be recognized during development. The language begins to develop from the child's birth. At first it is only the acoustic perception of one's speech and certain abilities of the organs of speech. There are several phases of language development that can be identified in the child's speech.

Most children's linguistic abilities are formed in a short period of time (Edwards and Beckman, 2008). In the early years of life, they are rapidly advancing from the use of simple symbols and rudimentary syllables of early vocal play to the use of longer words and pronunciations that contain recognized forms of most sounds in their native language (Edwards and Beckman, 2008). They hear and use language in the continuous social interactions of daily experiences. They are familiar with oral and written language over time and with a rich language environment, such as the variety of words used in extensive conversations, stories and interesting explanations (Snow et al., 1998).

The development of language is closely related to the child's social relationships and early experiences (Van Scoter, 2008). According to Van Scoter (2008), the game offers important opportunities to experience language in interactive activities such as reading stories, communication games and writing, all of which have an important influence on the development of oral and written language.

There is a pre-linguistic and linguistic phase (Trajkovskaa et al., 2010) of the development of a child's language. When the baby is born, the child begins to cry. This is the first step of the prelinguistic phase. This means that the child welcomes the outside world. It also proves it breathes. Subsequently, the new-born child uses his cry to send a message to the people who deals with him. At this stage, the sound the child produces can be related to a certain emotional condition that he has. For example, if the child is hungry, he would cry, if he / she is sad, he / she also cries, but otherwise, if the child is happy and satisfied then he or she would make specific sounds that would serve as indicators for his / her emotional state.

Vid Pecjak presents these developmental phases of the child's discourse: 1 . The cry that begins when the child opens its mouth and allows air to pass through the respiratory system; 2 . Vocalization, which means articulation of vocals; 3 . The expansion of sounds when the child is able to do; 4 . the contraction of sounds when certain sounds that exist in the discourse of the child no longer exist, especially those sounds that cannot be recognized in the discourse of the parents; 5 . the goo- goo refers to one sound to another; 6 . to real words when the child begins to use conscious speech.
When approaching pre-school, a spectacular evolution of language takes place. At the age of 5 , most children manage to speak fairly and grammatically, with a high ability to adapt to new situations. They start to create new words based on imitation of verbal models of parents or kindergarten. The preschool is able to communicate everything he wants and builds more and more longer and complex sentences (Cretu, 2009).

During the 6-10 years old, the most important evolution in the language area of development takes place: the writing-reading assimilation. Through this acquisition - a vocabulary enrichment and a more demanding regulation of speech are achieved by imposing the grammar requirements of writing and reading (Cretu, 2009).

Intervention strategies for preschoolers are various. The technology is an element to be taken into account to ensure the efficiency of learning and assimilation of information. The impact of new technologies on inter-human relationships is significant in social terms, providing new ways of socializing and sharing information. For children, language is the psychological process through which they communicate and interact with family, teachers and colleagues. The laptops, tablets or interactive tablets are modern means of development that children increasingly prefer to interact with; so this contributes to the formation and development of language. Stimulating the interest and involvement of young learners, the possibility of responding to the presented materials, the possibility for children to study at their own pace, the stimulation of communication and the development of language are indicators that can be achieved by accessing the technology by the beneficiaries, thus creating substantial improvements in the development and correction of speech through a single machine the computer (Dina, Ciornei, 2012).

Basic reading skills are probably of the most important skills in providing information and ideas in our culture. The reading skills are essential for all types of learning in school and for the development of productive thinking skills (Saunders, 2007). Reading is an active process that should be acquired at an early age of learning (Zainudin \& Yahya, 2006). Developing language to preschools children involves the use of several activities: children's stories, parents' moral experience, children's games, the quality and autonomy of their personal experiences. The time that parents and children spend together is very important. Therefore, the use of story books and leisure play are particularly important tools. (MeiJu et. al, 2014)

To develop language, children need to be presented as many words as possible in order to develop a rich understanding of their meaning and use. Teachers should introduce interesting and new words in the activities so that children can learn from each class activity (McGee, Richgels, 2003).

The teachers involved in the training and development of preschool language have to fulfil certain competences: openness and desire to engage in concrete lifelong learning activities, predominance of the need for curiosity, interest of the student showing understanding the meaning of the message. Increased interest in achieving learning outcomes, positive and autonomous attitude, the desire to succeed, and the accumulation of as much 
information as possible to help the accelerated development of child language. Intervention strategies must be implemented quickly and appropriately to the needs of the child, to ensure the best opportunity for success in the educational environment and social interactions. Specialists must work with parents to provide a solid foundation so that children are able to get an optimal integration into school (Wright, 2010).

\section{Research methodology}

- Groups Characteristics: two focus groups sessions were organised in this research project, each group having 6 participants. The members are preschool teachers from Bucharest having at least 2 years and maximum 10 years of experience in the public system of education. The recruitment of the participants was done on a voluntary basis by the moderator, according to two selection criteria: didactic career and pre-school education experience.

- The aim of the focus group is to provide information on teacher's intervention on children in some specific cases of speech difficulties.

- Focus group objectives: to list the most common difficulties that teachers encounter in language education; to identify the most frequent children's speech difficulties; to describe the family involvement in the case of children with speech difficulties; to list optimal ways of intervention, specific to language education.

- Preparation of interview: each focus group session was preceded by the presentation of the TIMLOGORO project. In the TIMLOGORO project, it is planned that an interactive platform for language therapy will be created. We want to estimate among practitioners invited to the discussion how extended is a possible need for such a language development tool. So, another goal of the focus group is to assess the needs of the practitioners for new products dedicated to language education. The interview guide is semi-structured around few themes.

- Themes discussed: 1. aspects of the verbal behaviour of children with speech difficulties; 2. children's socialization methods; 3. technology use in classroom; 4. intervention strategies centred on language development.

- Introduction: The rules of the discussion are presented by the moderator to the participants (no interest for consensus in opinion; any opinion is valued; everyone has to participate). The moderator launches the main topic (language development strategies at pre-school level) and subtopics (themes mentioned above). The discussion is strongly focused on the teacher's intervention in the management of speech difficulties at pre-school age. At the end of the two FG actions, the moderator tries to appreciate the future impact of the overall discussion.

- Duration and location: 90 minutes, Faculty of Psychology and Sciences of Education, University of Bucharest.

\section{Results}

The specialists and teachers considers that, at the final of kindergarten, the child should have the best abilities in: perceiving and accurately pronouncing and sounding all sounds and groups of the Romanian language, integrated into words; finding sounds and groups of sounds in different positions in the structure of the word; enhance the ability to separate words in syllables and syllables in sounds; enriching the active and passive vocabulary of children; explaining the meaning of words; stimulating children's creativity in oral expression.

\subsection{Speech deficiencies in preschool aged children}

All focus group participants agree that the pronunciation of the little child is far for being perfect. In teacher opinion, and according to their experience, the most common difficulties encountered by their children are:

- Teachers noticed that in the first few weeks, children who came directly from the family provided monosyllabic responses. At the exercises which are focused on children's ability to separate words in syllables, it is found that only a few children correctly split the words into syllables, the rest having difficulties especially in the monosyllabic words. Usually, they tend to divide this kind of word into two syllables.

- The difficulty of hearing is another issue due to the fact that there are many fundamental sounds and their variants. The exercises used by teachers have a wide variety. As a general rule, teachers use shorter words (1-2-3 syllables), with a low phonetic body - a particularity of oral communication. This precedes written communication which is much more elaborate than the oral one.

- A frequent and visible difficulty is related to the correct pronunciation of consonants. Many children still do not differentiate well $\mathrm{r}$ and $\mathrm{l}$ and $\mathrm{s}, \mathrm{z}$, and $\mathrm{j}$. For this reason, omission, substitution and inversion often occur in speech. Of the substitution cases (more frequent at pre-school age) are the following: the sounds $\mathrm{s}$ and $\mathrm{j}$ are usually replaced with $\mathrm{s}$ and $\mathrm{z}$; $\mathrm{S}$ and $\mathrm{z}$ with $\mathrm{t}$ and $\mathrm{d}$; $\mathrm{R}$ is sometimes replaced with $\mathrm{L}$.

- Teachers observed that usually, a large number of children learn how to develop sentences by using all the parts of the speech. Example: If at the beginning of kindergarten, the children made rather poor sentences in words (,The girl sings."), in the end of kindergarten, the other parts of speech: (,The little girl sings a lovely song.").

- In many games, the children had to make sentences after various images. If at the initial stages of the games the children were able to make simple sentences, up to 3 words. During activities, teachers noticed that most pre-schoolers know the meaning of words used in their dialogue, but each has a different understanding of the meaning of some words. After their training in vocabulary with exercises and games, they manage to gain self-control in expressive language.

According to FG participants, majority of abilities are developed due the systematic intervention of teachers. On this occasion, they express an intensive need to have a better support from the children's parents.

In terms of motivation for learning, participants did not notice a low motivation for these children, but a low level of self-esteem very prominent. That is why the success of the relationship with the child depends on how the teacher stimulates the child to participate in daily activities. They speak about a greater need for 
these children to be encouraged for any progress they have made. Mutual confidence is a feeling often invoked as the main feature of the interaction with these children.

\subsection{Social issues in preschool aged children}

The kindergarten attendance is a major issue for all teachers. Regarding this, the absence is usually objectively motivated, related to the younger children's health problems (in the first year of kindergarten). We mentioned earlier that some children encounter difficulties in pronouncing sounds and words, in finding singular or plural form of nouns, and in making simple sentences. Analysing the teachers' answers, these difficulties arise as a result of the fact that they have not regularly attended the kindergarten in the previous year. Sometimes, they are younger than their colleagues, having a poor experience or an improper family climate for acquiring a correct speech.

Teachers observed that children with a high rate of participation have a good quality of communication and dialogue, and have an expressive language that exceeds the level of biological age.

Usually, children who have socio-affective problems cannot express themselves correctly. In one or two cases, teachers mentioned that children lately diagnosed with some forms of mental retardation, follows a recovery program with specialists and speech therapists.

\subsection{Teachers' difficulties}

In the focus group discussions, it appears that every kindergarten has at least one child whose speech difficulties have a visible effect on the child's evolution.

The difficulties mentioned by teachers in working with these children are:

- $\quad$ All FG participants said that speech difficulties are prevented by specific actions in order to observe children's verbal behaviour and create ameliorative interventions. Thus, for the correction of speech impairments, the teacher - parents' collaboration ensures success. Unfortunately, collaboration with the family is, in most cases, difficult. Parents do not recognize the seriousness of the child's situation and consider that the teacher does not provide individualized support to solve the issue.

- A second difficulty is the lack of support that specialist staff can offer in dealing with this kind of cases: psychologist, counsellor, therapist, and doctor. The kindergartens is short in personnel/ in the psychological and medical expertise. The problem solving consists in an individual action of the family (visit the specialist). However, because of parent's conviction (often do not admit the existence of a deficiency), such an initiative take place only in situations with a clear risk, when children performances are very low.

- Another difficulty is due to the large number of children in the classroom, which considerably diminishes the personalized working time with these children. Practically, they interact very little with the teacher, and interactions with the equals are influenced by their poor verbal behaviour.

- Another difficulty is related to the quality of learning materials, which are not specifically designed for such special training situations. They must be continuously adapted by the teachers, and included in a personalized, systematic intervention strategy. This requires a considerable effort and time in using all resources.

- All children are digitally native. The discussion with focus group members is naturally oriented toward the subject of learning with the aid of digital instruments. The teachers recognize that they do not constantly use digital tools. Their experience is limited to the experimentation of some educational software based on language development. Digital platforms are not familiar to them, though they attach a great formative value to these language learning tools.

\subsection{Technology use}

During discussion, all teachers mentioned that the use of educational software is an effective learning tool that causes significant changes in the acquisition of language. After only a few learning experiences, they see the impact that virtual games and speech exercises have on correct expression and vocabulary. Educational software can be used in all types of activities. Most exercises also incorporate narrative segments that have allowed children to adopt appropriate communication strategies. Teachers prefers interdisciplinary designed software, for example: „Letters”, „Spring”, „Autumn”, „Colours and forms”, „Rex”, „Piti-Clic” CD collection, „Animated alphabet”, „English for children” etc.

In teacher's opinion, educational software has many advantages: provides a large amount of attractive game as a source of communication skills development; provide individualized language training, and effective feedback on child progress; simulates learning by means of attractive graphics, animation and sound elements (multimedia means).

There are also some disadvantages of educational software. The children should not be „forgotten”, in front of the computer, they must be supervised and even helped by their parents. Depending on age, the time spent causes visual fatigue or low attention.

\subsection{Current practices in language development}

All participants are interested to measure the efficiency of different practices in the language development well as to discover the most advantageous strategies for valorising them. According their expertise, games and tests are the most useful methods of learning. Many activities are specially organised by teachers in order to develop oral communication. For examples:

* knowing different situations (phone dialogue, peer dialogue, adult dialogue etc.);

* supporting a dialogue both as a speaker and auditor - „The Phone”, „At the Market” etc.;

* formulating the questions and answers - „Let's talk about this picture" etc.; 
* enriching the vocabulary: „Who is it, who are they?”;

* the correct expression of nouns in singular and plural (,I say one, you say many");

* understanding the meanings of words through games and learning activities (,Find the right word”).

In order to acquire the differentiation of the sounds and groups of sounds separated or in different positions in the structure of the word, there are various games in which the children were put to listen carefully to certain sounds, difficult to pronounce and then repeat them. For misspelled sounds, children have been asked to use them in words where the sound is in different positions.

Socio-affective games helped to develop the self-image that helps children to be more careful about social communication. The competition during playing games has also a positive impact.
By applying current tests, teachers intend to determine the level of communication skills. Correction of the test is always based on performance descriptors. For example, teachers can use descriptors and scores such us: insufficient (behaviour requiring support), sufficient (behaviour in special attention), good (developmental behaviour), very good (attained behaviour).

At the end of the FG discussion, the moderator asked participants to list three types of strategies that can be used in language development: blended learning, in-vivo training, digital platforms/software. Participants's options are graphically represented below. Blended learning is a better practice for language dvelopment, including digital resources and conventional methods used daily in the classroom.

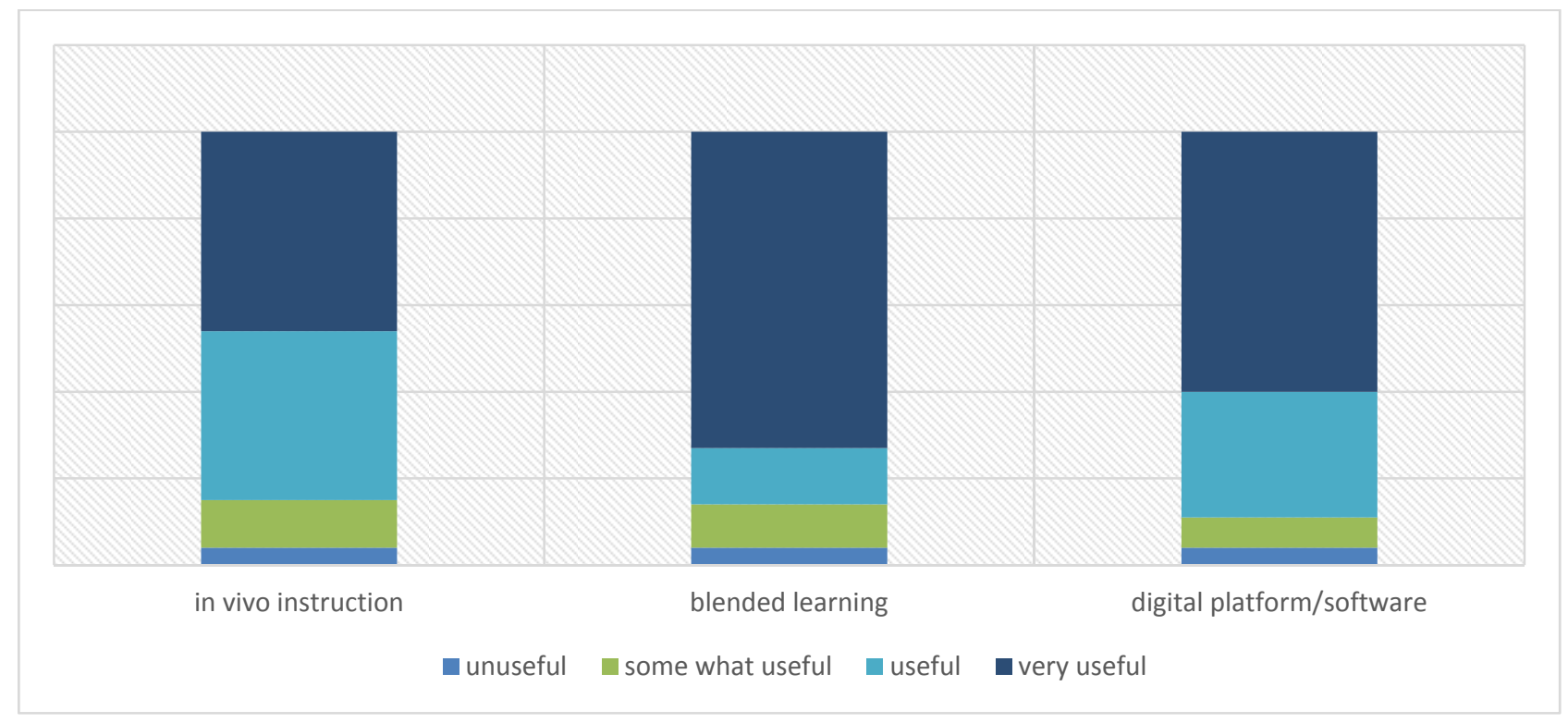

Figure 1. Strategies in language development

\section{Conclusion}

Compared with the school beginning, when children show a lot of confusion and hesitation in expressing language, at the end of the school year/kindergarten, teachers noticed that each child become a communication expert who try to self-correct. The teachers intervene every time to correct the wrong pronunciation or fix new knowledge in terms of language acquisition. With time, the interventions of the educator become increasingly rare.

In the collective interview, the following conclusion occurs: intervention in the case of children with speech difficulties is poorly supported. Creating an instrument as a resource for children's speech development is welcome. According to teachers, this tool (such us TIMLOGORO) should be accessible, low cost and easy to use. Durring discussion, they manifest a special interest for the use of an interactive multiplatform for communication skills development.

\section{Acknowledgements}

„This work was supported by a grant of the Romanian National Authority for Scientific Research and Innovation, CNCS/CCCDI UEFISCDI, project number PN-III-P2-2.1-PTE-2016-0068, within PNCDI III”. 


\section{References}

Berk, L., (2013). Child Development. Pearson Education.

Crețu, T., (2009). Psihologia vârstelor. Editura Polirom. Iași.

Dina, A.T., Ciornei, S.A. (2012). The Advantages and Disadvantages of Computer Assisted Language Learning and Teaching for Foreign Languages. Procedia - Social and Behavioral Sciences, vol. 76 , pp. 248-252. doi:10.1016/j.sbspro.2013.04.107.

Edwards J. \& Beckman M. E. (2008). Methodological questions in studying consonant acquisition. Clin Linguist Phon., vol. 22 (12), pp. 937-956. doi: 10.1080/02699200802330223.

Floyd, K., (2013). Comunicarea interpersonală. Editura Polirom. Iași.

Gokyer, N., (2015). The Views of Provincial School Inspectors on the Obstacles to Communication with Teachers in the Counseling and Inspection Process. Procedia, Social and Behavioral Sciences, vol.185, pp. 490-494. doi:10.1016/j.sbspro.2015.03.453.

Mei-Ju, C., Chen-Hsin, Huang, Y., Pin-Chen, H., (2014). The Beauty of Character Education on Preschool Children's Parent-Child Relationship. Procedia, Social and Behavioral Sciences, vol.143, pp. 527-533. doi:10.1016/j.sbspro.2014.07.431.

McGee, L. M., Richgels, D. J. (2003). Designing early literacy programs: Strategies for at-risk preschool and kindergarten children. New York: The Guilford Press.

Popa, M., (2006). Comunicarea: Aspecte generale şi particulare. Editura Paideea. București.
Saunders, K.J. (2007). Saunders, K. J. (2007), Word-attack skills in individuals with mental retardation. Ment. Retard. Dev. Disabil. Res. Rev., 13: 78-84. doi:10.1002/mrdd.20137.

Snow, C. E., Burns, M. S., Griffin, P. (Eds.). (1998). Preventing reading difficulties in young Children. Washington, D.C.: National Academy Press.

Trajkovskaa, A., Cvetkova, B., Atanasoska, T., (2010). Language development of a 1 to 2 years old child in Macedonian context: Morphological and semantic approach (case study). Procedia, Social and Behavioral Sciences, pp. 3094-3098. doi:10.1016/j.sbspro.2010.03.471.

Wright, R., (2010). Multifaceted Assessment for Early Childhood Education, Thousand Oaks: Sage, 2010. doi: http://dx.doi.org/10.4135/9781452243887.

Van Scoter, J., (2008). The potential of it to foster literacy development in kindergarten, In Voogt J. and Knezek G. (Eds.), International Handbook of Information Technology in Primary and Secondary Education, pp. 149-161. doi:10.1007/978-0-387-733159_9.

Vid, P., (1986). The development of language. Ed. Barret, Zagreb.

Zainuddin, H. \& Yahya, N., (2006). First and second language acquisition theories and models. Ed. E.N.W, Ariza. 